\title{
Assessment of tree resources outside forests: a lesson from Tanzania
}

\begin{abstract}
Navin Giri *
Tree resources outside forests (TROF) is becoming increasingly important for economic and ecological functions. Its assessment can be better done while we use both ground base tree measurements as well as remote sensing tools. In the present study, Line Intersect Sampling (LIS) method and Landsat TM Satellite image classification with maximum likelihood algorithm were used for field measurements and spatial distribution of TROF respectively at Yombo and Chasimba villages of Tanzania. Consistency of the results was checked by comparing the area covered by TROF and cashew nut cover in the study area calculated from both the methods. LIS method is found to be better suited for TROF assessment as there are only $25 \%$ of plots without trees, increasing the average number of trees per plot. Landsat TM image cannot give high accuracy in classification of TROF because of large pixel size $(30 \times 30 \mathrm{~m})$. In case of unavailability of high-resolution satellite imagery, classification accuracy can be enhanced using ground truthing data as well as visual interpretation of images implying local knowledge. TROF has covered about $41 \%$ of the land which shows the richness. Although there are limited new plantations, TROF is rich in stem volume per hectare $50 \mathrm{~m}^{3} / \mathrm{ha}$. Thus, in the condition of massive deforestation in nearby Ruvu North Forest Reserve, TROF of the study area can play vital role for the better use of tree products and consequently livelihood of the people. As deforestation continues in Nepal, the Nepalese TROF can play a valuable role for enhancing sustainable development and people's livelihoods. By extracting the Tanzanian experience, we can apply the line intersect sampling method for TROF assessment in Nepal.
\end{abstract}

Keywords: Tree resources outside forests, inventory, line intersect sampling, image classification, Landsat TM

$\mathbf{T}$ ree resources outside forests (TROF) or Trees Outside Forsts (TOF) is defined as 'trees on land not as forest and other wooded land' (FAO, 2000a), which includes farm land, urban and settlement areas, along roads, in home gardens, in hedge grows, scattered in the landscape and on pasture and rangelands.

In Nepal, TROF are being used as an integral part of daily life in the form of timber, small building material, fuelwood, fruits and medicines. They also contribute to maintaining the ecological balance through soil and water conservation, biodiversity conservation, carbon sequestration, etc.

Forest area in Nepal has decreased at an annual rate of 1.7 percent (DFRS, 1999), which has brought about soil degradation, loss of biodiversity and poverty, etc. Tree planting and management outside forests is therefore one of the solutions for minimizing these challenges. There is a huge potential for improving the welfare of poor communities through improved development and management of TROF (Unasylva, 2000). If we see the trend of regionally decreasing forest cover and increasing fragmentation, we might expect the relative importance of TROF to grow (Kleinn, 1999). In the context of forest area declination, it is time to include TROF in natural resource planning and consider it as integral component of landscape inventories. To do this, one of the first steps is to assess the resource to allow spatial, quantitative and qualitative characterization. Thus, tree planting outside forests and its assessment are nowadays considered as useful method for enhancing sustainable development and people's livelihood.

Realizing the growing concern and the importance of TROF, some countries in the world have adopted methodologies to assess the TROF depending on local situation. India, Morocco, Kenya, Costa Rica, and Sudan have already initiated work in assessing

\footnotetext{
* District Forest Office, Hattivan, Lalitpur. Email: giri@alumni.itc.nl
} 
TROF (FAO, 2000b). Some of the studies have used methods similar to the conventional forest inventory. In Nepal, many works have been carried out to assess private plantations but there is no inventory to properly assess TROF in Nepal (Amatya,et al., 2001).

Assessment of TROF has marked differences from traditional forest surveys. To assess the TROF, its higher heterogeneity and scattered distribution (compared to forest) should be considered, which makes the survey difficult, time consuming and expensive. The property size and land tenure structure of land where TROF are found are also heterogeneous, and generally very different from those of forestland (Kleinn, 2000). So, care should be taken while selecting the inventory method for TROF. The assessment problem carries on to the difficulty of spatial presentation of TROF in a map. Remote Sensing (RS) and Geographic Information System (GIS) tools as well as field survey data are useful to assess spatial distribution of TROF. Only high-resolution satellite image can easily display individual trees or objects with the width of one tree crown. The difficulty in low-resolution image is that on the same mapping unit one might find any combination of different classes of trees outside the forest (Kleinn, 1999).

Realizing the importance of TROF in Nepal, and also due to the lack of a proper method of its assessment in the country, the present paper highlights the methods used in Tanzania hoping that the same could be used in the Nepalese context.

\section{Study Area}

The study area of Yombo and Chasimba village lies in the Bagamoyo District of Tanzania. The District covers an area of $9842 \mathrm{~km}^{2}$ of which $855 \mathrm{~km}^{2}$ is covered by the Indian Ocean. Administratively, the District is divided into six Divisions: Miono, Mwambao, Yombo, Msata, Msoga, and Kwahurumbo. The TROF study area was Yombo and Chasimba villages of Bagamoyo District, which are, situated North-West of Ruvu North Forest Reserve. The villages are bordered by Ruvu River, Chombe River, Chatota River and the Ruvu forest reserve boundary. Yombo and Chasimba have 453 and 488 households respectively.

\section{Materials and methods}

Landsat thematic mapper imagery taken on September 1995 with spatial resolution of 30 meters was used to locate the study area, to generate raster map layers for sample selection and for supervised classification. Topographic map sheets of scale 1:50000 covering Bagamoyo, Yombo and Kawe were used to georeference images. Garmin 12 XL GPS receiver was used to locate sample points, to lay down

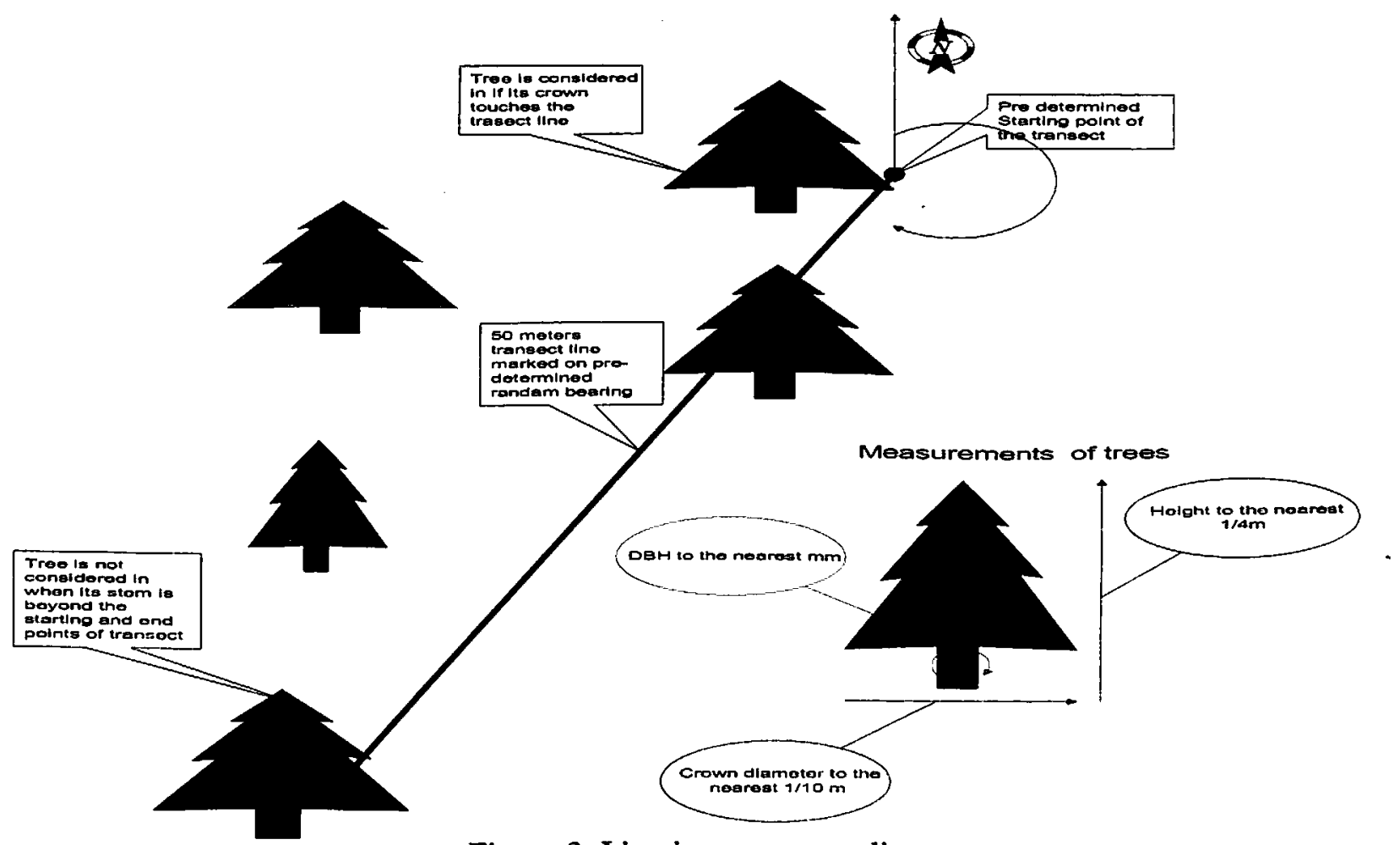

Figure 2: Line intersect sampling 
transect lines with random bearings, to record $\mathrm{X}$ and $Y$ coordinates of the trees along the transect lines and to navigate the desired coordinates according to sampling plan. Measuring tapes, Compass, Haga altimeter were used to lay down transect lines and to take measurements of trees along the transect lines. Ilwis 3.12 was used to classify images and to generate TROF cover maps. Microsoft Excel software spreadsheet was used for calculations of different parameters of TROF.

The form of inventory and assessment depends on the specific objectives. In order to respond to the information needs, a TROF inventory can provide quantitative data or maps of the resource (Kleinn, 2000). The conventional random sampling method for forest inventory is not suitable for TROF as there will be occurrence of more zero plots (plots without trees). When tree density decreases at constant plot size, average no. of trees/plot will decrease. Because of this, inventory cost will increase due to high plot variability and occurrence of more zero plots (Gier, 2003).

If we increase the plot size, it is difficult to layout and there will be more boundary trees and hence there will be risk of double counting or omission. To tackle with these difficulties, we need to replace the sampling plots by a sampling line and consider intersected trees (Gier, 2003). Thus, this method is called Line Intersect Sampling (LIS). This method is efficient for TROF inventory because, there is no need to layout plot and logical sequence of tree enumeration. Within Yombo and Chasimba village area (900 ha.), 36 points were randomly generated as starting points for $50 \mathrm{~m}$ transect lines. Transect lines were laid out with compass and measuring tape according to a random bearing. Trees were considered "in" and enumerated when their crown crossed the transect line and when the centre of their stem was inside either end of the transect line (see figure1). The position of each tree along the transect line was recorded, in order to know the distance from the starting point. Among other tree variables such as Diameter at Breast Height (dbh), height and crown diameter were measured. In this method, crown diameter as well as dbh and tree height are used to estimate stem volume per hectare.

The raw data of Thematic mapper (1995) image was georeferenced and resampled using the coordinates from scanned topographic maps during pre- fieldwork time. The colour composite of RGB 452 bands was made. The colour composite map was used in the field for orientation and discussion. Sample sets were created to classify the image both for whole TROF and Cashew cover maps. Training data collected (coordinates and sample) in the field was used for supervised classification. The Landsat TM satellite image was classified using Maximum Likelihood Classifier (MLC) algorithm with ground truthing data in Ilwis software. The MLC classifies all the pixels of an image with considering probability of a pixel to come under specific class based on the shape of and distance to the cluster of defined class in a feature space. The MLC considers not only the cluster centre but also its shape, size and orientation Janssen, 2001). Several GIS operations were used to come up with the different output maps and tables. Overlay operations were used to come up with accuracy assessments on image classifications of TROF cover and cashew cover maps.

\section{Results and Discussions}

\section{Line intersect sampling as sampling method}

Sampling design for TROF inventory is a big challenge. Major problem when discussing plot design option is the great variability of the spatial configuration and of the density of the TROF (Kleinn, 2000). If we use conventional random plot sampling, when tree density decreases at constant plot size, average number of trees per plot will decrease. Then, inventory cost will increase, due to high plot variability, and occurrence of more 'zero' plots. Best method is to replace the conventional plot sampling by a sampling line, and consider intersected trees (Gier, 2003). When comparing compact and more extended plot shapes, lines or strip-shaped plots are usually best capturing much variability along the transect (Kleinn, 2000). Considering these facts and comparing the results from various surveys, LIS seems logical to apply in TROF inventory in the study area. We can explain how the line intersects sampling method for TROF inventory is suitable. Let us compare the occurrence of 'zero' transect (plot) in different areas of TROF using Line intersect sampling (Table 1).

High percentage of zero trees $(70 \%)$ was seen in both Pithuwa and Gauriganj of Nepal and Ksanga and Kifuru of Tanzania. This shows that these TROF areas have low tree density and high plot variability, with less scattered trees. Better result was seen in 
Table1: Suitability of LIS Method

\begin{tabular}{lcccc}
\hline TROF sampling location using LIS & $\begin{array}{c}\text { No. of 'zero' plots } \\
\text { (Transect without } \\
\text { trees) }\end{array}$ & $\begin{array}{c}\text { Percentage } \\
\text { (\%) of zero } \\
\text { trees }\end{array}$ & $\begin{array}{c}\text { Total no. } \\
\text { of plots }\end{array}$ & Data source \\
\hline Pithuwa, Chitawan, Nepal & 35 & $70 \%$ & 50 & Nandakumara, 2001 \\
Gauriganj, Chitawan, Nepal & 35 & $70 \%$ & 50 & " \\
Chanika/Pugu, Kisarawe, Tanzania & 8 & $40 \%$ & 20 & Premakanta, 2002 \\
Kisanga/ Kifuru, Kisarawc, Tanzania & 14 & $70 \%$ & 20 & " Current study \\
Yombo/Chasimba, Bagamoyo, Tanzania & 9 & $\mathbf{2 5 \%}$ & 36 & Current \\
\hline
\end{tabular}

Yombo and Chasimba area of Tanzania with only $25 \%$ zero transect plots meaning thereby high tree density and low plot variability. The study area has dense distribution of TROF than other areas so that the trees could be better represented. So, LIS method is best suited as compared to the other study areas mentioned above because of presence of tree species with high tree density and crown coverage.

\section{TROF and Cashew area from Image} Classifications and spreadsheet calculations

The TROF and Cashew cover area obtained from the image classification are 367 and 212 ha respectively. Among this study area, according to the classification, $40.7 \%$ of area is covered by TROF out of which $23.5 \%$ is covered by Cashew nut trees. There are some thickets and shrubland, which are classified as others. The spatial distribution of TROF is more even than Cashew nut alone. There are several big patches (more than $0.5 \mathrm{ha}$.) of TROF in the study area which does not matches the TROF definition of FAO. Any assessment and mapping project of natural resources must state clearly the definitions used for classification of the resource (Kleinn, 1999). Although some TROF patches in the study area, according to FAO definition are forest, yet, are considered as TROF here because most of the trees are fruit tree plantations. The fruit tree plantation represents trees outside forests, whereas the tree plantation for timber represents the forest (Kleinn, 1999).

The overall accuracy of the image classification for TROF as a whole and cashew nut trees are $79 \%$ and $75 \%$ respectively (Tables 2 and 3 ). The Cashew nut class accuracy alone was only $67 \%$. This result of TROF accuracy is quite good considering the low resolution of Landsat TM image. In study carried out (Premakantha, 2002) on TROF cover classification, Landsat TM performs poor with only $66.7 \%$ accuracy. Good accuracy of Landsat TM 452 colour composite in this study could be attributed to as addition of visual aid interpretation of image during the training of ground truthing data. The visual interpretation of images is confirmed by a ground truthing campaign (Manuel, 1999). The use of visual aid interpretation may give good classification accuracy but at the same time it can underestimate the TROF area, as single tree cover is not considered as training sample. This is the limitation of Landsat TM satellite image in case of classifying TROF.

Table 2: Accuracy assessment for TROF

\begin{tabular}{lccc}
\hline \multirow{2}{*}{$\begin{array}{l}\text { Image } \\
\text { classification data }\end{array}$} & \multicolumn{3}{c}{ Training field sample data } \\
\cline { 2 - 4 } & TROF & Others & Total \\
\hline TROF & 15 & 01 & 16 \\
Others & 04 & 04 & 08 \\
Total & 19 & 05 & 24 \\
\hline
\end{tabular}

Overall accuracy $=19 / 24=79 \%$

TROF class accuracy $=15 / 19=79 \%$

Table 3: Accuracy assessment for Cashew nut

\begin{tabular}{lccc}
\hline \multirow{2}{*}{$\begin{array}{l}\text { Image } \\
\text { classification data }\end{array}$} & \multicolumn{3}{c}{ Training field sample data } \\
\cline { 2 - 4 } & $\begin{array}{c}\text { Cashew } \\
\text { nut }\end{array}$ & Others & Total \\
\hline Cashew nut & 10 & 00 & 10 \\
Others & 05 & 05 & 10 \\
Total & 15 & 05 & 20
\end{tabular}

Overall accuracy $=15 / 20=75 \%$

Cashew nut class accuracy $=10 / 15=67 \%$

The consistency of two classifications was further crosschecked by crossing the TROF cover and Cashew cover maps. About $86 \%$ of Cashew cover fall within the TROF cover. The remaining $14 \%$ area was misclassified as grassland and others. This is probably because of the same tonal interpretation of other TROF and grassland. From this study it can be said that, Landsat Thematic Mapper satellite image can be used to get the general picture of the TROF area but not in accurate figures because of limitations on spatial resolution. The accuracy of the image classification can be increased using more ground truthing data as well as visual interpretation of tonal and textural characteristics of image.

Crown or Canopy cover percentage is estimated for the whole population by: 


\section{$\mathrm{N} \mathrm{n}$ $C C \%=25 * 3.14 / L * N *\left\{\sum \sum(C d) i\right\}$}

where, $\mathrm{L}=$ length of transect line, $\mathrm{N}=$ no. of sampling unit, $(\mathrm{Cd}) \mathrm{i}=$ Crown diameter of each transect line. Knowing the values of $\mathrm{cc} \%$ of TROF in the study area, we can calculate the area of the TROF coverage in hectares. The area of TROF and Cashew nut coverage is estimated from sampling field data (crown cover \%) and image classification is given below (see table 4). The area estimation of TROF from image classification and crown cover percentage is nearer than the area estimation in cashew nut tree cover. The less area estimation from the image classification could be because of maximum signature (training) of grouped tree and not the single tree. The crown cover of single tree probably is lacking here. The best result can be achieved by training the sample both in single tree and grouped trees.

But, this is the limitation of Landsat TM satellite image. So, individual pixel should be selected very carefully in each cover class with the same Digital Number (DN) values (reflectance values) of the image in the feature space. The difference in area estimation of TROF and Cashew cover from Landsat TM image classification and field data spread sheet calculation are 1.23 and 5.66 ha. respectively. There might be question of accuracy of sampling method and process of field data taken as well as changes in TROF cover during eight years of time span. But, It is assumed that there would not have been any change in TROF cover from 1995 to 2003 , because fewer plantations is supposed to balance by old tree felling. Thus, we can only relate here the consistency (closeness) of the results of both the processes of image classification and spreadsheet calculation.

\section{Diameter class distribution}

TROF is distributed with large number of trees on $30-35$ and $35-40 \mathrm{~cm}$. diameter classes. There is less no. of younger trees. The distribution pattern of Cashew nut is similar that of overall TROF. But, there are some younger trees in case of coconut. We can observe the interesting and alarming diameter class distribution of TROF with number of trees we inventoried. The number of trees increases with the diameter classes. This shows that overall diameter distribution for the TROF found is rather unbalanced with the majority of trees enumerated being big and old trees. Sustainability of production is in danger here. Looking more specifically at cashew, the unbalanced character of the diameter distribution is even worse. There is an over-representation of big and old trees, whose production is seriously declining or has stopped all together. This may be due to a better market for coconut as compared with cashew nuts. Social survey verified this figure as majority of the farmers wanted to plant coconut, orange and mango but not cashew nut because of having poor market. The diameter class distribution of TROF can be discussed by comparing it with another district Kisarawe, Tanzania (Data source: Premakantha, 2002). $54 \%$ of trees of Yombo and Chasimba area has crown diameter of more than 10 meters, whereas Chanika/Pugu area has only $15 \%$. This shows the richness of TROF in terms of crown cover in Yombo and Chasimba area of Bagamoyo.

\section{Distribution according to stem volume per hectare}

Because there was no appropriate volume equation available for the trees found in study area, volume was calculated using the following general volume equation: $\mathrm{V}=$ ghf. Where, $\mathrm{V}=$ volume, $\mathrm{g}=$ basal area, $\mathrm{h}=$ height, $\mathrm{f}=$ form factor. All the TROF of the study area are assumed as highly branched tree as they have less competition with other trees, unlike forests. Because of this, they produce less stem volume and hence the value of form factor was assumed as 0.5 for the calculation of stem volume.

Estimated volume per hactare for a transect was calculated as follows:

$\mathrm{V} / \mathrm{A}=\mathbf{k} / \mathbf{L} \boldsymbol{\Sigma}\left(\mathrm{V} / \mathrm{C}_{\mathrm{dcst}}\right)$, Where $: \mathrm{V} / \mathrm{A}=$ volume per hectare for a transect, $k=10,000 \mathrm{~m}^{2}$ per hectare and $\mathrm{L}=$ transect length $(\mathrm{m}) . \mathrm{V} / \mathrm{C}_{\mathrm{d} \text { est }}$ equals ratio of tree volume to estimated crown diameter $\left(\mathrm{m}^{3} / \mathrm{m}\right)$ for a tree, which was calculated by regression analysis. Data

Table 4: Area estimation from image classification and field measurements

\begin{tabular}{ccccc}
\hline Cover type & $\begin{array}{c}\text { Study area } \\
\text { in hectare }\end{array}$ & $\begin{array}{c}\text { Area from Image } \\
\text { classification in ha. }\end{array}$ & $\begin{array}{c}\text { Area from crown } \\
\text { covers percentage } \\
\text { (field data) in ha. }\end{array}$ & $\begin{array}{c}\text { Difference in } \\
\text { percentage }\end{array}$ \\
\hline TROF cover & 900 & $367(40.77 \%)$ & $378(42 \%)$ & 1.23 \\
Cashew cover & 900 & $212(23.55 \%)$ & $252(28 \%)$ & 4.45 \\
\hline
\end{tabular}


Yombo/Chasimba Area

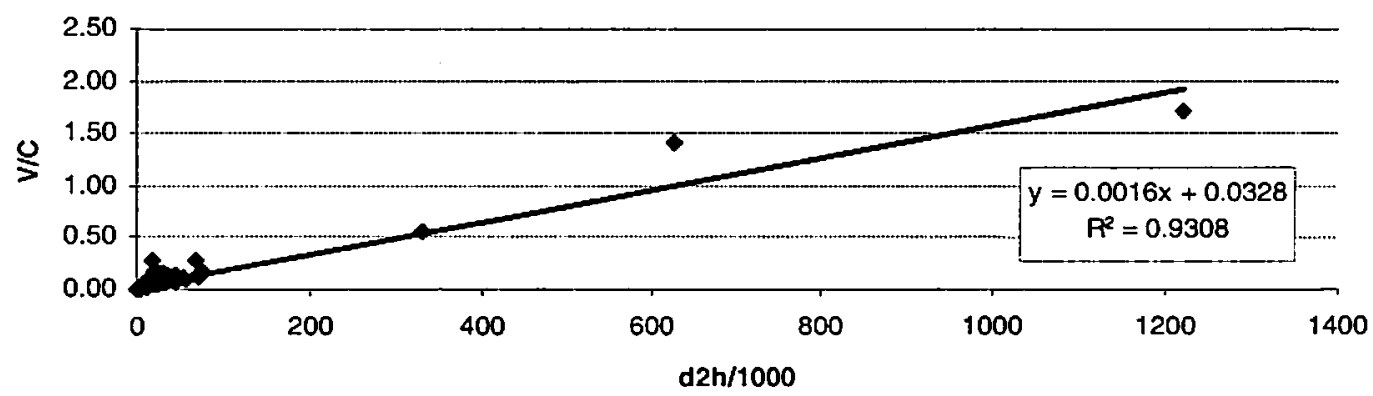

Figure 2 : Relationships between $V / C$ and $d^{2} h$

of each tree inventoried was entered to an Excel Spread sheet. Then $\mathrm{V} / \mathrm{C}$ was calculated and scatter plot of $V / C$ over $d^{2} h / 1000$ were made, which are highly correlated (see figure 2 ).

Because of three outlier trees, majority of points are grouped together. The estimated volume per crown diameter $\left(V / C_{\text {est }}\right)$ was then calculated for all trees followed by the calculation of sum of estimated volume per crown diameter $\left(\mathrm{V} / \mathrm{C}_{\mathrm{ess}}\right)$ for all trees in each transect. Finally, volume per hectare for each transect was calculated by taking the sum of $\mathrm{V} / \mathrm{C}_{\text {est. }}$. From this the average volume per hectare for the whole study area was calculated dividing the sum of total estimated volume per hectare by no. of plots (36).

Stem volume per hectare of the study area was calculated in excel spread sheet and found to be 50 $\mathrm{m} 3 / \mathrm{ha}$. The Ruvu North Forest Reserve nearby the study area is degraded Miombo forest and is being managing as production forest. The stem volume of the woodland of the reserve is very less i.e., 11.5 $\mathrm{m} 3 / \mathrm{ha}$. (ITC Group report, 2003). This reserve is being heavily destroyed mainly by charcoal production during the last two decades. Stem volume per hectare of TROF in different areas can be compared with the study area to see the richness of TROF. The outcome of the stem volume / ha. of different areas are given below (table 5).
Above shown stem volume per hectare of different regions shows that Kisanga \& Kifuru and Buyuni \& Pugu area of Tanzania is richer in TROF than Nepal. And Yombo and Chasimba area is richest in stem volume per hectare of all these areas. This could be due to early fruit tree plantation in the study area. Villagers told that, Cashew was planted in the study area as well as in Tanzania in the 1950s and 1960s.

\section{The Nepalese context}

TROF play important role especially in the Middle Hills and Terai of Nepal. As there is no study carried out to assess the TROF in Nepal so far, developing a methodology to assess the same is necessary. The random plot sampling is the widely used method for forest resources assessments. However, this method may not be cost effective in TROF assessment where there is a tendency to have plots without trees because of the nature of configuration and the low densities of TROF. Considering those factors, the Line Intersect Sampling (LIS) method can be selected to collect data on TROF of Nepal. The assessment of Tree Resources Outside Forests has already been done in Gauriganj and Pithuwa area of Chitawan District of Nepal using the Line Intersect Sampling method by Nandakumara of Srilanka as a student of ITC, The Netherlands.

Table 5: Comparison of TROF assessment

\begin{tabular}{lccl}
\hline \multicolumn{1}{c}{ Study area } & $\begin{array}{c}\text { Number of } \\
\text { samples }\end{array}$ & $\begin{array}{c}\text { TROF stem vol./ha. } \\
\text { (m3/ha.) }\end{array}$ & Source data \\
\hline Yombo/Chasimba, Tanzania & 36 & 50.0 & Current study \\
Ruvu North Forest Reserve & 15 & 11.5 & Premakanta, 2002 \\
Kisanga \& Kifuru, Tanzania & 20 & 17.98 & " \\
Buyuni,Chanika \& Pugu Kjiyengani, Tanzania & 20 & 28.57 & " Nandakumara, 2001 \\
Gauriganj, Chitawn,Nepal & 50 & 7.3 & " \\
Pithuwa, Chitawan, Nepal & 50 & 5.82 & , \\
\hline
\end{tabular}




\section{Suggestions}

Line intersect sampling method for TROF inventory is appropriate to the study area as there is more even distribution of TROF than in other areas of Tanzania. Because of this, there is less percentage of zero transects (zero trees in each transects) which increases average no. of trees per plot. This can be applied for TROF survey in the country like Nepal to save time, money and to get reliable data on those areas with high heterogeneity and variability of trees. For an accurate TROF classification, Landsat TM satellite image is not appropriate, as single tree cannot be recognised in $30 \mathrm{~m}$ pixel. However, it can classify generalised TROF cover resulting in overall picture of the TROF distribution. Knowing the local knowledge of the study area, accuracy of the classification can be increased using both ground truthing data as well as visual interpretation with tonal and textural characteristics of image.

\section{References}

Amatya, S. M. Parajuli, A.. V. Shrestha, S. M. Bhattarai, G. P. 2001. Proposal on Methodology for Assessment of Forest Resources and TOF in Nepal. National Expert Consultation on Global Forest Survey (GFS), 21-22 May 2001. Eds S. M. Amatya, R. Kharel and S. M.Shrestha, Department of Forest Research and Survey, Kathmandu, Nepal, 42-44.

DFRS 1999. Forest resources of Nepal (1987-1998): Publication No. 74 Department of forest research and survey, HMG Nepal and FRISP, The Government of Finland.

FAO 2000a. Trees outside forests. Global Forest Resource Assessment (FRA), Main Report. Food and Agriculture Organizations, Rome, Italy, 3944.
FAO 2000b. South Asia. Global Forest Resources Assessment. Main Report. Food and Agriculture Organizations, Rome, Italy.

FAO 2001. Trees outside forests: Towards rural and urban Integrated Resources Management. Contribution to the forest resources assessment 2000 report. Food and Agriculture Organizations, Rome, Italy.

Gier, A. D. 2003. Lecture notes on Line Intersect Sampling, ITC, The Netherlands.

Janssen, L. L. F. 2001. Principles of Remote sensing. ITC, Enschede, the Netherlands.

Kleinn, C. 1999. Paper presentation on "Tree Resources Outside the Forests in Central America; A Regional assessment approach based on Remote sensing and field survey.

Kleinn, C. 2000. Trees outside Forests: On largearea inventory and assessment of Trees outside Forests. Unasylva- No. 200.

Manuel, F. G. 1999. Paper presented at the workshop on Integrated Analysis and Management of Renewable Natural Resources in Mozambique, Maputo, The Mozambican Land Use/Land Cover Mapping Project.

Nandakumara, P. A. 2001. Individual Final Assignment Report, Variation of Tree resources Outside Forests in relation to Physical and Social factors, in Chitawan districts, Nepal. ITC, The Netherlands.

Premakanta, K. T. 2002. Individual Final Assignment Report, Assessment of Trees Outside Forests. ITC, The Netherlands.

Unasylva 2000. Trees Outside Forests; International workshop on off-farm tree resources of Africa. No. 200. 